\title{
Inclusão intelectual no ensino regular: perímetro e área de regiões poligonais
}

\author{
Intellectual inclusion in regular education: perimeter and area of \\ polygonal regions
}

\author{
Susana Michelim Collareda ${ }^{1}$ \\ Rogério Fernando Pires ${ }^{2}$
}

\begin{abstract}
Resumo. Este artigo apresenta os principais resultados de uma pesquisa cujo objetivo foi analisar as possíveis contribuições de uma proposta utilizando materiais manipulativos para o ensino de perímetro e área de regiões poligonais com alunos do 9. ${ }^{\circ}$ ano do Ensino Fundamental portadores de necessidades intelectuais. A pesquisa de cunho qualitativo, na modalidade estudo de caso, ocorreu em uma escola de ensino regular na cidade de Mairinque, no interior de São Paulo, e contou com a participação de três estudantes portadores de necessidades especiais (deficiência intelectual) e três alunos auxiliares, não portadores de necessidades especiais. As atividades realizadas com esses alunos tiveram a intenção de observar e analisar a interação dos estudantes portadores de necessidades especiais com o meio e a presença da mediação defendida nas ideias de Vygotski. Ao final do estudo, foi possível constatar que os materiais manipulativos auxiliaram o desenvolvimento da ludicidade e exerceram importante função na aprendizagem dos estudantes. A inserção dos materiais manipulativos no processo de construção do conhecimento contribuiu para a compreensão das noções de perímetro e área, ressignificar a relação mediadora com os colegas, valorizando sua ajuda, e reconhecer no material formas e métodos utilizados na vida cotidiana. Esses materiais facilitaram o entendimento dos conteúdos abordados, proporcionando forma lúdica para o aprendizado.
\end{abstract}

Palavras-chave. Déficit intelectual. Educação inclusiva. Materiais manipulativos.

\footnotetext{
${ }^{1}$ Secretaria de Estado da Educação de São Paulo, collaredasusana@ gmail.com

${ }^{2}$ Instituto de Ciências Exatas e Naturais do Pontal da Universidade Federal de Uberlândia, rfpires@ufu.br
} 


\begin{abstract}
This article presents the main results of a research whose objective was to analyze the possible contributions of a proposal using manipulative materials for the teaching of perimeter and area of polygonal regions with students of the 9th grade of Elementary School with intellectual disabilities. The qualitative research, in the case study modality, took place in a regular school in the city of Mairinque, in the interior of São Paulo, and had the participation of three students with special needs (intellectual disability) and three auxiliary students, not with special needs. The activities carried out with these students were intended to observe and analyze the interaction of students with special needs with the environment and the presence of mediation advocated in Vygotski's ideas. At the end of the study, it was found that the manipulative materials helped the development of playfulness and played an important role in student learning. The insertion of manipulative materials in the knowledge construction process contributed to the understanding of the notions of perimeter and area, redefining the mediating relationship with colleagues, valuing their help, and recognizing in the material forms and methods used in daily life. These materials facilitated the understanding of the contents covered, providing a playful way for learning.
\end{abstract}

Keywords. Intellectual déficit. Inclusive education. Manipulative materials.

\title{
1 Introdução
}

Educar é uma tarefa que requer muita responsabilidade perante uma sociedade. A educação transforma o modo de pensar, de agir e de compreender o mundo, abre portas para infinitas possibilidades de se encontrar em um ambiente. O educador é a fonte do conhecimento para aquele que inicia sua jornada na escola, ele é o mediador. A escola é o ambiente que proporciona diversas trocas que direcionam as mudanças sociais.

A transformação que o ambiente escolar provoca vai além do que se tem escrito em livros. A interação social transforma as conexões que o indivíduo possui com relação ao seu conhecimento de mundo.

Abordado na Constituição de 1988, no artigo 208, que o atendimento educacional especializado aos portadores de necessidades especieias seria feito preferencialmente na rede regular de ensino, a lei somente foi reconhecida em 11 de setembro de 2001, efetivandose o que há muito se cogitava por meio de lei em todo o Brasil: uma mudança expressiva na educação inclusiva e especial, com as novas Diretrizes Nacionais para a Educação Especial na Educação Básica na Resolução CNE/CEB n. ${ }^{\circ}$ 2/2001, no artigo 2. ${ }^{\circ}$ :

Os sistemas de ensino devem matricular todos os estudantes, cabendo às escolas organizarem-se para o atendimento aos educandos com necessidades educacionais especiais, assegurando as condições necessárias para uma educação de qualidade para todos (BRASIL, 2001, p. 68,[1]). 
De acordo com o artigo citado, as escolas deveriam se organizar para receber os alunos com necessidades especiais. Nessa perspectiva, alguns anos depois, durante uma reunião em 2003, promovida pelo município de Mairinque/SP, o tema foi a inclusão na rede municipal de crianças com necessidades especiais nas classes regulares. A partir dessa reunião, a rede municipal decidiu trazer os educandos das classes especiais para as classes regulares, obedecendo às diretrizes da nova lei, o que motivou ações que deram origem a esta pesquisa, com intuito de construir ferramentas que ajudassem no ensino desses educandos.

Reunindo-se Matemática, Geometria e inclusão intelectual, surgiram muitos desafios a serem superados, e é uma parte ínfima dessa tricotomia que será tratada neste artigo, demonstrando como as relações pessoais e interpessoais podem facilitar o modo de aprendizagem dos educandos com necessidades especiais.

Foram escolhidos três educandos com diagnóstico de deficiência intelectual registrados na Companhia de Processamento de Dados do Estado de São Paulo (Prodesp) de uma escola pública de Mairinque, com o objetivo de investigar como os materiais manipulativos poderiam colaborar com o processo de ensino e aprendizagem.

\section{Diretrizes curriculares nacionais para a educação in- clusiva e as deficiências na sociedade}

Em virtude de Constituição Federal, em 1988, apontar como um dos objetivos fundamentais "promover o bem de todos, sem preconceitos de origem, raça, sexo, cor, idade, e quais outras formas de discriminação", surgiu a indagação: o indivíduo com necessidade especial pode estar inserido em um ambiente em que todos os outros alunos, tidos “normais", estão?

Em 2009, o Conselho Nacional de Educação publica as Diretrizes Operacionais para o Atendimento Educacional Especializado na Educação Básica, que visa complementar e suplementar a Educação Inclusiva, cuja característica é promover um incremento ao ensino regular, colocando à disposição profissionais que ajudem os educandos com necessidades especiais, de forma a facilitar seu ensino dentro das salas de aula comuns.

Portanto, a Política Nacional de Educação Especial possui como perspectiva assegurar a inclusão a educandos com dificuldades e transtornos globais de desenvolvimento e altas habilidades e superdotação, orientando os sistemas de ensino regular, dando suporte teórico e prático para educadores e gestores de unidades escolares, a fim de garantir a transversalidade da modalidade de educação especial desde a educação infantil até a superior. Ao mesmo tempo, assegura que as estruturas das escolas e os recursos tecnológicos 
estejam disponíveis, agregando maior eficiência ao processo de ensino e aprendizagem.

Aqueles que apresentam alguma necessidade especial encontram em sua trajetória diversos obstáculos que os limitam desenvolver uma efetiva interação social. O ambiente limitador impede o acesso ao saber e, a esse não acesso, atrela-se à ideia de limitação social, em que ele não encontra espaços na sociedade, não consegue interagir socialmente e, como consequência, não estimula suas faculdades mentais.

A clínica está especialmente interessada na possibilidade de distinguir esses sintomas por meio dos quais o retardo mental pode ser diagnosticado, determinar essa forma de déficit e distingui-la de outro quadro clínico semelhante e nada mais (VYGOTSKI, 2012, p. 131,[6] - tradução nossa).

Nessa citação de Vygotski, vê-se claramente como se tratavam os estudos sobre as deficiências mentais. O conceito e o entendimento acerca da deficiência sempre provocaram diversas discussões emblemáticas, em que a medicina trouxe definições que caracterizavam esses indivíduos como incapazes, o que tornava cada vez mais difícil inserir o processo de conhecimento formal em suas vidas.

A deficiência é algo que gera estudos e indagações referentes a seus aspectos de caracterização, que são analisados por alguns autores e, após um processo de desenvolvimento teórico e prático, tenta não enxergar essas deficiências apenas como algo estrutural, e sim de uma construção social.

Deficiência não é um resultado direto de um distúrbio biológico, mas um modo de constituição decorrente do impacto provocado pela formação psicofisiológica da pessoa em seu ambiente social (RAAD; TUNES, 2011, p. 34,[3]).

Coloca-se a indagação no sentido de que, mesmo que esse indivíduo tenha nascido com alguma deficiência orgânica, ele deve receber os cuidados que qualquer criança no seu desenvolvimento obteria. Talvez alguns precisariam de algo a mais pela sua necessidade, uma maior atenção. Se a toda e qualquer criança, desde o primórdio de seu desenvolvimento, fossem dados estímulos positivos que a fizesse se sentir encorajada e capaz de se desenvolver em qualquer ambiente, isso faria uma enorme diferença em sua vida, o que de fato é raro acontecer.

Segundo a Convenção sobre os Direitos das Pessoas com Deficiência, promulgada pela ONU em 2006, encontramos em seu artigo primeiro que as deficiências podem ser de origem física, sensorial e intelectual. Com elas surgem as limitações que prejudicam o desenvolvimento e consequente interação social. Assim, a Convenção tem o propósito de promover, proteger e assegurar que as pessoas com deficiência desfrutem os seus direitos com dignidade e de acordo com os direitos humanos fundamentais (BRASIL, 2008,[2]). 


\title{
3 Abordagem do desenvolvimento intelectual por meio de estímulos
}

Desde o nascimento, o homem recebe influência externa, que é parte de sua melhor adaptação ao ambiente novo e hostil fora do ventre de uma mulher. Atrelado a isso, ao indivíduo são dados estímulos necessários para seu desenvolvimento. Seja no campo intelectual, físico e motor, todos precisam de um auxiliador em suas descobertas e com o processo de desenvolvimento de suas faculdades mentais. Segundo Silva (2014, p. 50,[4]):

\begin{abstract}
Para Vygotski, o ser humano possui natureza social, visto que nasce em um ambiente carregado de valores culturais, e sem a relação com o outro, o homem não se faz homem. Ou seja, é na relação com o outro que se fundamenta a constituição cultural do ser humano. De acordo com seus estudos, afirma que o homem se constitui enquanto tal a partir da relação que estabelece com o outro enquanto ser social. Dessa maneira, a cultura torna-se elemento da natureza humana num processo histórico que, durante o desenvolvimento da espécie e do indivíduo, constitui a função psicológica do homem, ou seja, o aperfeiçoamento do intelecto humano está estreitamente atrelado às relações sociais, que têm como produto o conhecimento, a cultura. E a cultura é considerada como sendo a totalidade das produções humanas, isto é, ela é produto da vida social.
\end{abstract}

Os indivíduos são seres sociais e devem, por essência, ser conscientes de que para a compreensão e desenvolvimento mental é necessário que receba estímulos externos por meio de diversas linguagens, seja em gestos, símbolos ou palavras. Sem essa interação em sociedade, o desenvolvimento não ocorre, a sociedade não evolui. Ainda em Silva (2014, p. 78,[4]):

\footnotetext{
Segundo Vygotski, a criança nasce apenas com funções psicológicas elementares e é a partir do aprendizado da cultura que estas funções se transformam em funções psicológicas superiores. Entretanto, essa evolução não se dá de forma imediata e direta, as informações recebidas do meio social são intermediadas de forma explícita, ou não, pelas pessoas com as quais interage.
}

A criança inicia seu aprendizado ao querer um objeto e apontar para ele, de forma que uma pessoa externa compreenderá que aquele gesto é uma maneira de comunicação para se obter o que deseja, gerando assim um tipo de linguagem. A criança, com o passar do tempo, entenderá as diversas maneiras de se comunicar com as pessoas responsáveis pelo seu cuidado e sofre influência do meio, a fim de ser guiada a evoluir diante da sociedade em que vive.

Acredita-se que o intelecto primitivo se desenvolveu por meio de estímulos externos, sociais, impulsionados por outros indivíduos e signos. A compreensão dos signos e a relação social trazem conexões e formas de linguagem que auxiliam as faculdades mentais a entender o que está no seu ambiente e que é necessário evoluir desenvolvendo funções psicológicas superiores. 
Para Vygotski, o pressuposto da constituição social dos seres humanos assentase na noção de cérebro como um sistema aberto, em outras palavras, de acordo com as experiências sociais dos sujeitos e a utilização de diferentes instrumentos e símbolos como linguagem e tecnologia, os homens terão várias possibilidades de funcionamento cerebral (TOSTA, 2012, p. 63,[5]).

Colocando em questão a ideia dos deficientes intelectuais na experiência de troca social, eles podem, por meio de seus déficits, construir novos estímulos, chamados por Vygotski (2012, [6]) de compensação.

Quando da percepção de uma deficiência e incapacidade, se estimularmos o indivíduo devidamente, surgem então possibilidades compensatórias. A educação e seus educadores não podem deixar de levar em consideração a superação, que é inerente de todo ser humano ser capaz se adequar.

Por essa razão, surgem motivos pelos quais é necessário analisar quais ferramentas vão auxiliar esses educandos a construir novas conexões cerebrais, para que seja garantida a compreensão sobre os conteúdos a serem aprendidos em sala de aula, como também os auxiliem no crescimento mental perante suas necessidades de vida social.

A defesa da semiótica como algo fortemente inerente ao desenvolvimento do saber é uma maneira evolutiva de construção de linguagem mais acessível e que contribui para a troca de informações. É nesse sentido que, mesmo com as definições e limitações que a sociedade ainda persiste em colocar sobre os indivíduos com deficiência intelectual, é possível, em face de todo o exposto, a estimulação para melhor desempenho cognitivo em sociedade. É fazer da sociedade algo que acrescente sobre a vida desses indivíduos, pois por meio disso poderão ser obtidos resultados satisfatórios.

\footnotetext{
Considero que agora é possível e necessário limitar-nos a assinalar que as conclusões, feitas de maneira geral e que, do ponto de vista teórico, reestruturam o enfoque pedagógico tradicional da criança com retardo mental, estando conectadas de modo direto com os atuais objetivos concretos que são levantados para nossa escola hoje (VYGOTSKI, 2012, p. 147,[6]).
}

O deficiente intelectual não pode mais ser um caso somente de estudo médico e biológico. Devem ser pesquisados meios que levem esses indivíduos a conseguir capacidades para que possam viver plenamente no mundo social. Levantar hipóteses pedagógicas e aplicá-las a essas pessoas e divulgar aquilo que se obtiver por meio dessas pesquisas, não se limitando a conclusões solitárias.

\section{Metodologia de pesquisa}

"O estudo da criança com retardo mental deve basear-se principalmente em um teste qualitativo, e não na determinação quantitativa do defeito” (VYGOTSKI, 2012, p. 193, [6] - tradução nossa). 
A pesquisa em questão focou um estudo qualitativo na modalidade de estudo de caso, que segundo Yin $(2005$, p. 97,[7]) pode ser:

[...] tratado como importante estratégia metodológica para a pesquisa em ciências humanas, pois permite ao investigador um aprofundamento em relação ao fenômeno estudado, revelando nuances difíceis de serem enxergadas "a olho nu". Além disso, o estudo de caso favorece uma visão holística sobre os acontecimentos da vida real, destacando-se seu caráter de investigação empírica de fenômenos contemporâneos.

Assim, foram participantes três educandos com diagnóstico de portadores de necessidades especiais intelectuais, de uma escola pública de Ensino Fundamental, localizada no município de Mairinque, interior de São Paulo.

As atividades foram realizadas dentro de sala de aula da escola. As tarefas tiveram em média duração de 1 hora e 40 minutos e os dados foram produzidos e coletados por meio dos registros dos estudantes e gravação de vídeo das ações realizadas por eles quando realizavam as atividades. O intuito da gravação foi entender no momento da análise as respostas dadas pelos investigados como, também, capturar reações e certos comportamentos que não são possíveis de serem registrados no papel, pois considerando que a mediação e a interação social são fundamentais para o desenvolvimento intelectual do indivíduo, esses comportamentos são fundamentais para a obtenção de resultados na pesquisa.

Com a professora pesquisadora e os três alunos pesquisados, participaram três alunos auxiliadores, com o objetivo de ajudar na dinâmica das atividades, os quais foram selecionados com critério de maior socialização com os alunos estudados.

Para a realização das atividades da intervenção foram utilizados os seguintes materiais:

- 12 tampas de MDF.

- Destas, três foram transformadas em geoplanos.

- 63 peças de figuras geométricas confeccionadas em EVA.

- Casa de boneca confeccionada em MDF.

- Placas de pastilhas de vidro.

- Calculadora, régua, trena, compasso, transferidor, esquadro, entre outros materiais.

O processo para execução e análise das atividades teve o intuito de investigar o desempenho de alunos com deficiência intelectual diante dos materiais manipulativos e investigar a contribuição que essas ferramentas poderiam dar a esses educandos. $\mathrm{O}$ embasamento 
teórico foi sustentado pelas ideias de Vygotski sobre estímulo, compensação, superação, mediação, desenvolvimento proximal e real.

Primeiramente, ocorreu o planejamento das atividades realizadas pelos educandos, seguido da elaboração e pesquisa da fundamentação teórica.

Na sequência, foram confeccionados os materiais manipulativos utilizados nas atividades. Definido o local de realização das atividades, seguiu-se para sua aplicação, durante as quais foram feitas fotos, gravações de imagens e áudios, com intuito de realizar uma análise mais detalhada em outro momento.

\subsection{Caracterização das atividades}

Foram realizadas com os estudantes cinco atividades que envolveram as noções de área e perímetro de regiões poligonais, que serão apresentadas a seguir.

- Atividade 1: Polígonos e perímetros - A atividade consiste em construir com elásticos no geoplano figuras geométricas, diferenciando e conceituando polígonos e não polígonos; construir polígonos diferenciando-os por meio dos lados (quantidade e tamanho); determinar o perímetro das figuras construídas com a contagem dos espaços, estabelecidos como unidade de medida; aplicação de questionário, cujo objetivo era a compreensão do conceito de polígonos e não polígonos; observação dos segmentos de reta; compreender as unidades de medida; construção por parte dos educandos das regiões poligonais quadradas, retângulo e triângulo retângulo; incentivar a coordenação motora; interação dos alunos com os participantes auxiliadores.

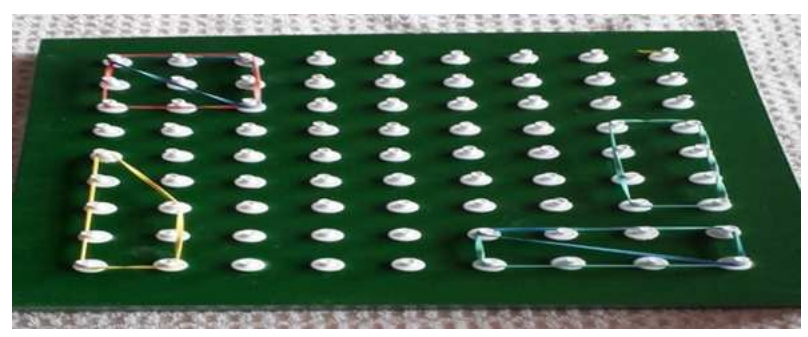

Figura 1: Geoplano com elásticos.

- Atividade 2: Fixando polígonos e perímetro - Foram usadas figuras geométricas confeccionadas em EVA, as quais os alunos manuseando, comparando e fazendo marcações puderam confirmar os conceitos aprendidos no geoplano. Houve também registros do cálculo do perímetro de algumas figuras. Introduziram-se a unidade de medida centímetro e o conceito de ângulo reto. Nessa tarefa, o objetivo 
era refletir sobre as diferentes figuras geométricas; reconhecer as figuras quadrado, retângulo e triângulo retângulo; reconhecer outras unidades de medida.

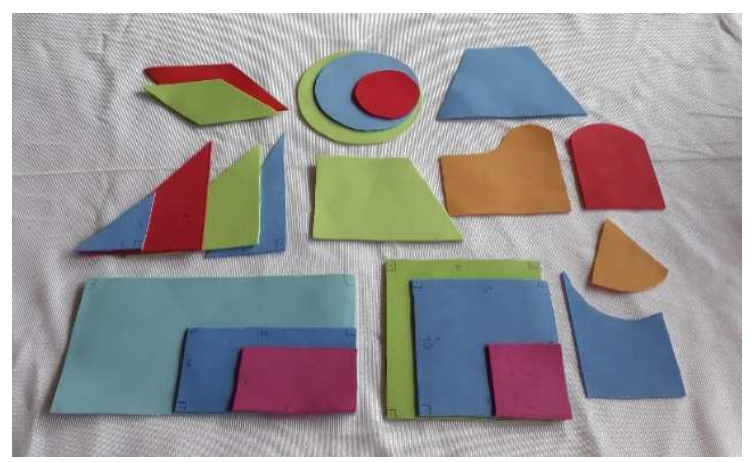

Figura 2: Figuras geométricas utilizadas.

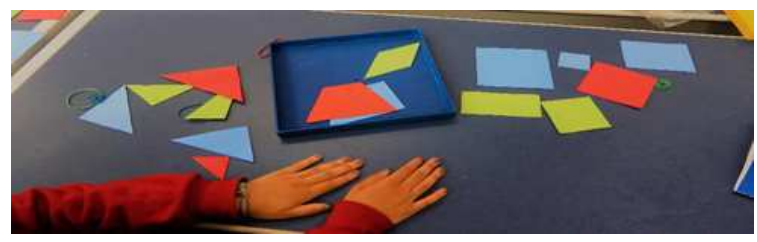

Figura 3: Separação das figuras geométricas.

- Atividade 3: Área - A tarefa consiste em recobrir um tabuleiro com pastilhas de vidro, reconhecendo área como preenchimento de uma superfície plana e a pastilha como unidade de medida de área. Foi determinado que para definir a área de uma superfície bastaria saber a medida da base e da altura. Essa atividade tinha como objetivo compreender o significado de base e altura; os alunos calcularem área; constituição de uma relação do conteúdo abordado com seu cotidiano.

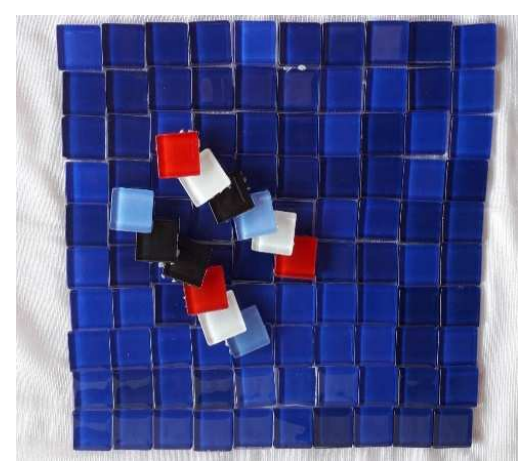

Figura 4: Pastilhas.

- Atividade 4 - Fixação do conceito de área. Com peças de EVA quadradas, os estudantes puderam reprisar a atividade anterior com as pastilhas. Retornaram-se aos 


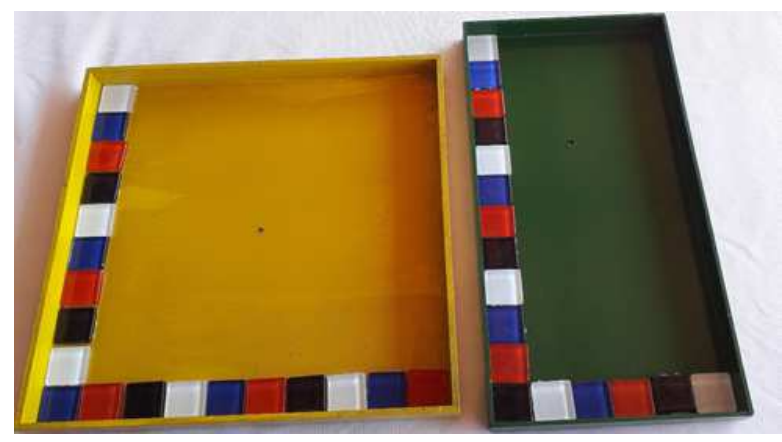

Figura 5: Tabuleiro em MDF.

registros anteriores de perímetro e fizeram os cálculos da área das mesmas figuras. O objetivo era analisar a efetiva compreensão do conceito de área; sedimentação de conceitos como unidade de medida em centímetros quadrados, lado, altura e símbolos matemáticos.

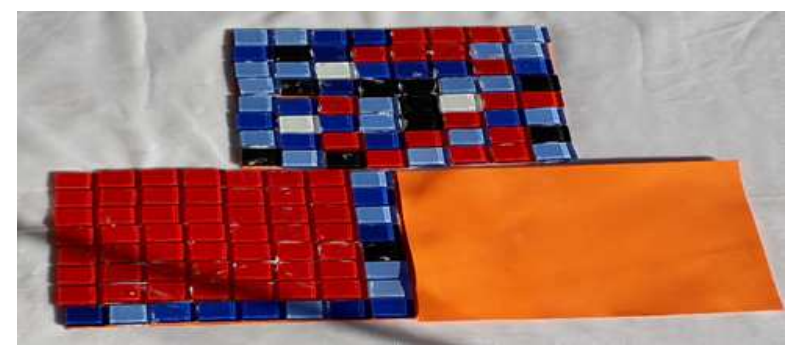

Figura 6: Pastilhas sobrepostas.

- Atividade 5 - Avaliação. Em uma casa de bonecas, os estudantes mediram o seu contorno, determinando o perímetro. Mensuraram e determinaram quantas pastilhas eram necessárias para recobrir um dos cômodos da casa, fizeram medições e construíram peças em EVA para revestir um dos cômodos da casa de bonecas. O objetivo era a sedimentação de todos os conceitos abordados em atividades anteriores, tomando como modelo a representação de uma casa em MDF; relacionar os conceitos que aprenderam com objetos e situações de seu cotidiano.

As atividades apresentadas foram realizadas pelos participantes da pesquisa, em algumas vezes com a intervenção da professora/pesquisadora, quando necessário. 


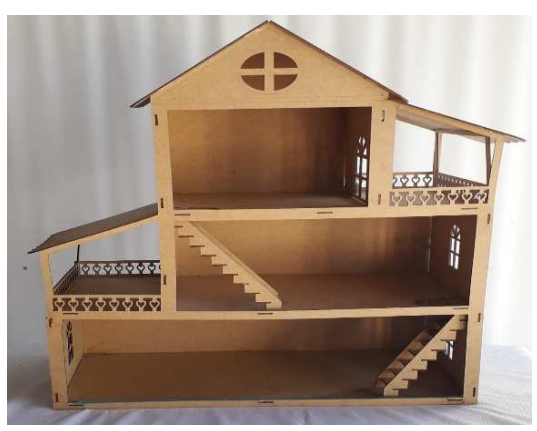

Figura 7: Casa de boneca.

\subsection{Caracterização dos estudantes investigados antes da realização das atividades}

Os três estudantes portadores de necessidades especiais que participaram da pesquisa, são alunos da primeira autora há dois anos. Durante esse tempo, a pesquisadora veio observando esses alunos e elaborando relatórios sobre seus desenvolvimentos e dificuldades a fim de melhor planejar o seu trabalho e deixar a gestão da escola a par dos progressos e dificuldades deles. Os apontamentos feitos nesses relatórios foram sintetizados e as principais características deles compuseram esse trabalho com a finalidade de ao final da pesquisa, num movimento comparativo, evidenciar possíveis avanços, o surgimento de novas dificuldade ou a permanência das limitações observadas antes da realização do estudo.

Os participantes apresentavam limitações na aprendizagem e algumas dificuldades que iam além de conceitos matemáticos. Para que se possa entender melhor a situação, algumas características de cada participante serão descritas a seguir.

- Aluno G: Dificuldade com conceitos simples; aprendizagem muito limitada; não sabe ler e escrever; sem domínio de operações básicas; precisa de atividades simples adaptadas para compreensão; desenvolvimento motor levemente comprometido; boa comunicação; relaciona-se bem socialmente.

- Aluno M: Compreende conceitos simples; aprendizado lento e simplificado; domina a leitura, mas tem dificuldade com escrita e interpretação; não domina operações básicas da Matemática; reconhece algoritmos; não sabe fazer uso da calculadora; desenvolvimento motor normal; boa comunicação; boa interação social.

- Aluno N: Compreende conceitos simples; aprendizado lento; domina leitura, escrita, mas tem dificuldade de interpretação; sabe realizar contas básicas, e com ajuda consegue compreender conceitos mais complexos; reconhece algoritmos; di- 
ficuldade de atenção; desenvolvimento motor normal; boa comunicação; dificuldade nas relações sociais. Como pode ser observado, as dificuldades iam desde a leitura e escrita, até mesmo na mobilidade, que dificultava a participação do estudante em tarefas simples, por exemplo, cortar papel com uma tesoura.

\section{Resultados: caracterização dos estudantes após a rea- lização das atividades.}

Após a realização das atividades, partiu-se para o processo de análise por parte da professora pesquisadora (primeira autora), cujo objetivo foi observar se os materiais manipulativos construídos foram enriquecedores no processo de ensino e aprendizagem dos alunos com deficiência intelectual.

A análise baseou-se em caracterizar os alunos antes da intervenção, como supraexposto, e observar as contribuições dos materiais manipulativos para o desenvolvimento após a aplicação das atividades. Portanto, seguem os resultados do desenvolvimento de cada aluno após intervenção:

- Aluno G: Melhorou a coordenação motora, conseguindo cortar e manusear a régua, o que antes da intervenção era algo bem difícil; passou a arriscar e fazer atividades sem necessitar de mediação de outro; definiu polígonos como figuras como "linhas retas"; reconheceu o círculo como não polígono; reconheceu e pôde definir outros polígonos, além do triângulo; conseguiu determinar os ângulos retos nas figuras apresentadas; conseguiu contar até 20 e reconheceu o número 26; define perímetro como "em volta"; mediado, consegue fazer os cálculos do perímetro; reconhece área como preenchimento de uma superfície (usa o termo "enche tudo"); mantémse a dificuldade de compreender os resultados das operações.

Ao analisar as gravações em vídeo e alguns registros realizados pelo estudante, foram evidenciadas tais características explicitadas para o aluno $\mathrm{G}$ e, foi possível perceber que essa evolução foi gradual e a presença do aluno auxiliar e as intervenções para professoras foram essenciais, uma vez que ele se mostrava muito inseguro e dependente no começo, fato considerado normal no processo de aprendizagem, uma vez que Tosta e Vigotski (2012, [5]) consideram que a interação social é fundamental para o desenvolvimento do indivíduo e, que tudo que se faz com o auxílio do outro hoje, o sujeito poderá fazer sozinho amanhã. Fica evidente nesse caso que a zona de desenvolvimento proximal permeou o processo de aprendizagem.

- Aluno M: Superou as dificuldades de medição com auxílio da régua; reconhece e quer fazer uso de outros instrumentos de medida como o transferidor; executa a 
maioria das tarefas sem mediação, somente precisando de pequenas intervenções e a cada atividade melhora o desempenho e autonomia de executar as atividades propostas; define polígono como "linhas e fechado"; reconhece, nomeia e até observa propriedades dos polígonos estudados; define perímetro como "total da volta"; reconhece os ângulos retos e agudos nos polígonos; supera medições e registros para o cálculo de perímetro e medição de ângulo; supera a dificuldade no uso de calculadora; reconhece como recobrimento de superfície.

Já o aluno M não apresentava dificuldades de interação social e, dominava algumas habilidades como a de leitura, realizava operações básicas, além de ser bastante comunicativo. No entanto, analisando o material coletado, foi possível evidenciar que o contato com os materiais foi muito importante para começasse a reconhecer um polígono, aprendesse a descrever o que seria a medida do perímetro e aprendesse a manusear objetos como régua e calculadora. Esses avanços na aprendizagem do estudante podem estar relacionados com a inteiração do indivíduo com o meio defendida por Vygotski (2012, [6]), uma vez que esse autor defende o desenvolvimento psíquico e a aprendizagem acontecem a partir das inteirações realizadas pelo sujeito em desenvolvimento.

- Aluno N: Reconhece e faz uso de outros instrumentos de medição, como a do transferidor; executa sem mediação a maioria das tarefas e torna-se mediador para seus colegas; define não polígonos como "figuras que têm curvas", polígonos como "todos os lados com linhas retas" e "linha fechada"; reconhece e nomeia e até observa propriedades dos polígonos estudados; reconhece os ângulos retos e agudos nos polígonos; define perímetro como "a soma dos lados", principalmente nessa tarefa se mostrou mediador; reconhece área como recobrimento de uma superfície; supera medições e registros para o cálculo do perímetro e medição de ângulos; determina os cálculos para a obtenção da área de uma superfície; supera as expectativas tornando-se interessado, participativo e mediador.

Analisando o material produzido por $\mathrm{N}$ durante a pesquisa, foi possível evidenciar que a sua habilidade de se expressar e a comunicação foram fundamentais para a obtenção dos resultados apontados anteriormente, pois a sua habilidade na manipulação de instrumentos de medição e a sua capacidade de comunicação fez com que ele pudesse não somente realizar as suas atividades, mas também, auxiliar seus colegas, fato que contribuiu com a existência de uma zona de desenvolvimento proximal entre os próprios investigados.

Assim, observando a síntese da caracterização dos estudantes, fazendo um comparativo com a caracterização feita antes da realização da pesquisa, foi possível observar que muitos deles desenvolveram habilidades e se apropriaram de conceitos importantes para a aprendizagem matemática, porém vale ressaltar que esse possível ganho é fruto da interação dos indivíduos com o meio e com tudo o que a ele pertence. Essa hipótese está 
presente nas ideias defendidas por Vygotski em sua teoria, na qual o autor defende que é fundamental para o processo de aprendizagem que o sujeito tenha contato com o meio e com tudo o que dele faça parte.

Portanto, a intervenção criou um contexto de aprendizagem, que permitiu que os estudantes manipulassem os materiais, interagissem uns com os outros e com a professora também. Esses fatos certamente despertaram nos alunos um sentimento de "capacidade"; eles se sentiram capazes de aprender e, ainda, ao manipularem os materiais elaborados para a realização da pesquisa, eles puderam compreender os conceitos envolvidos e entender como tais conceitos podem ser aplicados em situações reais.

\section{Considerações finais}

Diante dos resultados a partir da análise dos dados com base nas teorias de Vygostski sobre estímulos, compensação, superação, mediação, desenvolvimento real e proximal, foi possível evidenciar que os educandos obtiveram graus diferenciados no aprendizado sobre perímetros e áreas de regiões poligonais ao serem apresentados aos materiais manipulativos.

Pôde-se observar que os materiais exerceram papel fundamental no desenvolvimento de habilidades inerentes aos conceitos abordados e que isso possibilitou que os educandos com deficiência intelectual estudados aprendessem de maneira mais efetiva.

Em todas as tarefas, o contexto e a interação social foram de extrema importância para a execução exitosa das tarefas propostas aos estudantes, considerando que o objetivo da pesquisa foi analisar as possíveis contribuições de uma proposta utilizando materiais manipulativos para o ensino de perímetro e área de regiões poligonais com alunos do $9 .^{\circ}$ ano do Ensino Fundamental portadores de necessidades intelectuais.

Então, é possível inferir que os materiais puderam contribuir com o aprendizado em geral e principalmente do perímetro, que ficou internalizado em todos os educandos.

A manipulação trouxe prazer ao aprendizado. Pode-se citar também a contribuição na relação social entre os educandos com deficiência intelectual e os alunos auxiliares, que não têm deficiência; foi de suma importância para que os portadores de necessidades especiais se sentissem incluídos nas atividades e acreditassem em suas potencialidades. Colaborou ainda para que a pesquisadora evoluísse em seu modo de ensino, uma vez que os estudos preliminares realizados para o planejamento e elaboração das atividades, bem como o convívio com os estudantes, fizeram a professora refletir sobre a sua prática pedagógica, e cada imprevisto foi fundamental para o replanejamento das ações.

A interação com os materiais manipulativos durante as atividades foi a maior contribuição, na visão da pesquisadora, pois os educandos se mantiveram interessados e parti- 
cipativos, o que não se observava em sala de aula. A todo momento, eles se mantiveram atentos às tarefas, às explicações e às ações dos colegas. Por meio deste trabalho, ficam como propostas pesquisas futuras para que se desenvolvam estudos com materiais concretos na área da Matemática que possam realmente ajudar no ensino e aprendizagem de pessoas com necessidades especiais. E que esses materiais sejam de fato usados nas escolas públicas como meio de adequação do currículo.

\section{Referências}

[1] BRASIL. Ministério da Educação. Diretrizes Nacionais para a Educação Especial na Educação Básica. Secretaria da Educação Especial. Brasília: MEC/SEESP, 2001.

[2] BRASIL. A Convenção sobre Direitos das Pessoas com Deficiência comentada. Coordenação Ana Paula Crosara Resende e Flavia Maria de Paiva Vital. Brasília: Secretaria Especial dos Direitos Humanos, Coordenadoria Nacional para Integração da Pessoa Portadora de Deficiência, 2008. Disponível em: https://www.governodigital.gov.br/documentosarquivos/ A $\div 20$ Convencao\%20sobre $200 s \div 20$ Direitos $\div 20$ das $\% 20$ Pessoas \%20 com20Deficiencia\%20 Comentada.pdf. Acesso em: 9 fev. 2018.

[3] RAAD, L. F.; TUNES, E. Deficiência com latogênese. In: MARTINEZ, Albertina Mitjáns; TACCA, Maria Carmen Villela Rosa (org.). Possibilidades de aprendizagem: ações pedagógicas para alunos com dificuldade e deficiência. Campinas: Alínea, 2011.

[4] SILVA, I. G. O espaço e o ambiente escolar como elementos de mediação para o desenvolvimento dos sujeitos com deficiência. Dissertação de Mestrado. Universidade Estadual do Oeste do Paraná, 2014.

[5] TOSTA, C. G. Vigotski e o desenvolvimento das funções psicológicas superiores. Revista Perspectivas em Psicologia, Uberaba, v. 16, n. 1, p. 57-67, jan./jun. 2012. Disponível em: http://www.seer.ufu.br/index.php/ perspectivasempsicologia/article/view/27548. Acesso em: 27 fev. 2019.

[6] VYGOTSKI, L. S. Obras escogidas: fundamentos de defectología. Tradução Julio Guillermo Blank. Madrid: Machado Grupo de Distribuição, 2012. 
[7] YIN, R. K. Estudo de Caso: planejamento e métodos. Trad.: Daniel Grassi. Porto Alegre: Artmed, 2005.

Submetido em 19 mar. 2020

Aceito em 13 mai. 2020 